\title{
Social Norms Theory and Measurement in Entertainment-Education: Insights from Case Studies in Four Countries
}

\author{
Amy Henderson Riley, Farren Rodrigues, \\ and Suruchi Sood
}

\section{Social Norms in Entertainment-Education}

Entertainment-education (EE) is formally defined in other texts as "the process of purposely designing and implementing a media message to both entertain and educate in order to increase audience members' knowledge about an educational issue, create favorable attitudes, shift social norms [emphasis added by us], and change overt behavior" (Singhal \& Rogers 1999; Singhal \& Rogers, 2002; Singhal \& Rogers, 2004, p. 5). Although this definition of EE has evolved over time, social norms remain a fundamental part of this creative communication strategy (Poindexter, 2004). But while social norms have been considered since the beginning

\footnotetext{
A. H. Riley $(\bowtie)$

Jefferson College of Population Health, Philadelphia, PA, USA

e-mail: Amy.Riley@jefferson.edu

F. Rodrigues $\bullet$ S. Sood

Drexel University, Philadelphia, PA, USA

e-mail: ss3724@drexel.edu

(C) The Author(s) 2021

L. B. Frank, P. Falzone (eds.), Entertainment-Education Behind the

Scenes, https://doi.org/10.1007/978-3-030-63614-2_11
} 
of EE, specifically how social norms have been measured in research and evaluation, and what that has meant in terms of EE practice, has been an evolution that has mirrored the advancement of social science theory and research. Two of us (Amy and Suruchi) have been fortunate to help advance the science and practice of EE in our careers as academic researchers. This chapter presents case studies of social norms from our shared experiences leading research projects in four global settings, some personal experiences, and lessons we learned along the way. Farren was a graduate assistant at the time of this writing and helped us immensely in what we hope is an accessible chapter for EE practitioners and enthusiasts that furthers a dialogue on EE research and practice, particularly around social norms.

The Sabido television programs in Latin America were some of the first theoretically grounded examples of modern EE. From the beginning, folks thought about EE's impact on social norms. A retrospective qualitative study of the program Simplemente Maria found young women signed up for adult literacy classes in the countries where the program aired and thus EE researchers drew conclusions regarding exposure and social change (Singhal, Obregon, \& Rogers, 1995). The Indian soap opera Hum Log was an early replication of the EE format outside of Spanishspeaking countries and included educational information on family planning, gender equality, and social norms (Singhal \& Rogers, 1988). A qualitative study analyzed the text of letters written to the show and drew conclusions about social norms, as did results from a survey (Ryerson, 1994). As modern social science evolved, so too did attempts to measure social norms as a result of EE using advances in technology. For example, an evaluation of the recent Indian television show Main Kuch Bhi Kar Sakti Hoon analyzed the content of 1.7 million phone calls, analysis which would have been technologically challenging in early evaluations of EE (Wang \& Singhal, 2018). EE research has since followed the theoretical advances in social norms over time.

\section{Social Norms Constructs AND TheOretical UnderpinNINGS}

The literature on social norms approaches using EE can appear overwhelming to both practitioners and academics alike. There are a plethora of constructs, theories, and models, which can be confusing and seemingly 
esoteric. To keep it simple, social norms are the unwritten rules that guide human behavior; they are what we do, what we believe others do (construct 1 in Table 11.1), and what we believe others think we should do (construct 2) (WHO, 2010). For their existence, social norms inherently require a reference group (construct 3 ), that is a network of people to whom we identify and compare ourselves (Lapinski \& Rimal, 2005). This reference group determines norms because identity with a specific group influences whether or not a behavior is considered normative within the group and, in turn, may predict whether or not a new behavior will be adopted (Goldstein, Cialdini, \& Griskevicius, 2008). Members of a group expect, are expected to follow, and are motivated to follow norms because of expectations of sanctions for non-adherence (construct 4) and rewards for adherence (construct 5). Finally, collective norms (construct 6) are

Table 11.1 Summary of six social norms constructs

\begin{tabular}{|c|c|c|}
\hline Constructs by many names & Definition & $\begin{array}{l}\text { Theorists/theoretical } \\
\operatorname{model}(s)\end{array}$ \\
\hline $\begin{array}{l}\text { 1. Descriptive norms / } \\
\text { empirical expectations }\end{array}$ & $\begin{array}{l}\text { Beliefs about what other } \\
\text { people do (i.e., perceived } \\
\text { prevalence) }\end{array}$ & $\begin{array}{l}\text { Cialdini, Reno, and } \\
\text { Kallgren (1990) } \\
\text { Bicchieri }(2006,2016) \\
\text { Mackie, Moneti, Shakya, } \\
\text { and Denny (2015) }\end{array}$ \\
\hline $\begin{array}{l}\text { 2. Injunctive norms/ } \\
\text { subjective norms/ } \\
\text { normative expectations }\end{array}$ & $\begin{array}{l}\text { Beliefs about what others } \\
\text { approve of/think people } \\
\text { should do }\end{array}$ & $\begin{array}{l}\text { Cialdini et al. (1990) } \\
\text { Ajzen and Fishbein }(1980) \\
\text { Bicchieri }(2006,2016)\end{array}$ \\
\hline 3. Reference group & $\begin{array}{l}\text { A group of people that a } \\
\text { person feels a connection } \\
\text { or identity with }\end{array}$ & $\begin{array}{l}\text { Lapinski and Rimal (2005) } \\
\text { Costenbader, Lenzi, } \\
\text { Hershow, Ashburn, and } \\
\text { McCarraher (2017) }\end{array}$ \\
\hline 4. Sanctions/punishments & $\begin{array}{l}\text { Beliefs about the perceived } \\
\text { sanctions/punishments }\end{array}$ & $\begin{array}{l}\text { Bendor and Swistak (2001) } \\
\text { Rimal and Real (2005) } \\
\text { Rimal (2008) } \\
\text { Mackie et al. (2015) }\end{array}$ \\
\hline 5. Benefits/rewards & $\begin{array}{l}\text { Beliefs about the perceived } \\
\text { benefits/rewards }\end{array}$ & $\begin{array}{l}\text { Rosenstock (1974) } \\
\text { Bandura (1977) } \\
\text { Rimal and Real (2005) } \\
\text { Rimal (2008) }\end{array}$ \\
\hline 6. Collective norms & $\begin{array}{l}\text { Actual prevalence of a } \\
\text { behavior }\end{array}$ & $\begin{array}{l}\text { Kaggwa, Diop, and Storey } \\
(2008) \\
\text { Storey and Kaggwa (2009) } \\
\text { Sedlander and Rimal } \\
(2019)\end{array}$ \\
\hline
\end{tabular}


what people actually do, that is, the actual prevalence of a behavior. While we realize we are oversimplifying a bit, we acknowledge that this work draws from the work of various scholars across several disciplines, and our aim here is simply to summarize the social norms constructs and provide key citations from where these constructs are selected.

The social norms constructs outlined above emerge from a host of different theories. Several theories of individual change include social norms, such as the theory of planned behavior, developed by Ajzen and Fishbein (1980), which provides a way to predict intentions and subsequently behavior through perceived subjective norms. This theory indicates beliefs have to take into consideration the strength of a norm and whether or not to comply with it (Montano \& Kasprzyk, 2008). The theory of normative social behavior (Rimal \& Lapinkski, 2015; Rimal \& Real, 2005; Lapinski \& Rimal, 2005; Rimal, Lapinski, Cook, \& Real, 2005) is another theory practitioners may be familiar with. This theory relies on descriptive and injunctive norms (explained in Table 11.1), and also incorporates "outcome expectations." This idea that expectations of socially sanctioned rewards and punishments motivate behaviors is critical when designing EE by allowing intended audiences to vicariously experience benefits.

Other theorizing includes social norms as part of a larger equation of behavior and social change. The theory of bounded normative influence (Kincaid, 2004), for example, is a communication theory that derives from the diffusion of innovations (Rogers, 2003) approach by postulating that every innovation begins as a deviation from existing social norms. According to the theory of bounded normative influence, social norms and behavior occur within relatively bounded, local subgroups of a social system rather than the system as a whole. Across communication theorizing, norms are considered to be an intermediate step that have to change in order to accomplish behavioral outcomes. The use of a broader socialecological perspective in this type of theorizing situates individuals within their broader environment (inter-personal, community, institutional, societal, etc.) and allows for analysis at different levels of influence and the development of strategies to impact them.

Another set of key theories are narrative persuasion theories. The term narrative persuasion is an umbrella term that comes from the field of communication and encompasses a set of theoretical constructs that each explain how storytelling (or narrative) engenders change. These constructs include narrative transportation (Green \& Brock, 2000), narrative engagement (Busselle \& Bilandzic, 2009), and identification with characters 
(Cohen, 2001). In short, these ideas explain how the innate properties of storytelling are what that bring about change in a person's knowledge, attitudes, and beliefs as a result of exposure to EE programs. Have you ever gotten so lost in a story that you blocked out the rest of the activity happening in the physical room you are sitting in? Have you ever yelled at the television for your favorite character to "watch out!" or cried when something sad happened in a beloved movie? As humans and communicators, we are instinctively persuaded by stories when we get lost in the world of the story and its characters. There is, in fact, a growing body of research that illustrates people are more likely to remember and apply didactic health information when they experience such information in a narrative versus a non-narrative format, and when narratives and characters are designed to be similar to themselves (Frank, Murphy, Chatterjee, Moran, \& Baezconde-Garbanati, 2015). This idea of narrative persuasion is not new. Research looking at what is called "parasocial interaction"-or a perceived relationship with a fictional character-emerged in the midtwentieth century (Horton \& Wohl, 1956). Both Suruchi and Amy's research careers have built on the theoretical ideas of storytelling vis-à-vis EE. In fact, Suruchi wrote her doctoral thesis on the role of audience involvement and the effects of EE from the radio soap opera Tinka Tinka Sukh in India (Sood, 2002), while Amy wrote hers on social norms, narrative persuasion, and EE from the Ouro Negro radio program in Mozambique (Riley, Sood, \& Sani, 2019).

These various theories use different terminology. However, the underlying premise across social norms theorizing is that norms influence behavior and vice versa. If normative beliefs can be changed, behavioral change will ensue and if behavior change occurs, then norms will change.

Recent and growing interest in social norms theory has resulted in conceptual models that focus on how social norms influence behavior and social change (we know, we know, we started with theories, and are now talking about models, but hang in with us here). The Flower for Sustained Health is one such conceptual model that illustrates how resources, and individual, social, and institutional factors shape the social and gender norms at play (Institute for Reproductive Health, 2019; Heise \& Cislaghi, 2017; CARE, 2017). Another broad model based on practical experiences focuses on the norm-related determinants of behavior change. This module, synthesized in the manual Everybody Wants to Belong, looks at the behavioral determinants of social norms with multiple social norms components grouped into sociological factors that affect psychological factors 
like attitudes, cognitive bias, and self-efficacy, and in turn the adoption of a new behavior (Petit \& Zalk, 2019). A third and final framework, consolidated under the acronym ACT, attempts to measure social norm change around harmful practices, specifically Female Genital Mutilation (FGM), resulting from communication interventions using a social-ecological perspective (Sood et al., 2020). ACT stands for the different sections of the framework (two sections per letter): (1) Assess what people know, feel, and do; (2) Assess normative factors; (3) Consider the context, especially gender and power; (4) Collect information on social networks and social support; (5) Track individual and social change over time; and (6) Triangulate all data analysis.

Growing interest in measuring social norms has resulted in recent guides, which have mostly focused on quantitative techniques (Institute for Reproductive Health, 2019; Petit \& Zalk, 2019). Though there is widespread agreement that qualitative methods are useful for examining norms (e.g., using vignettes), much of the measurement literature has not tapped into participatory research as a technique to understand and evaluate norms (Sood et al., 2020). Additionally, despite all of these theories, models, and measurement frameworks, a thorough understanding of how social and behavior change interventions address social norms is yet to be articulated. The following four case studies illustrate how we measured and researched social norms in different ways in EE projects designed with the express intention of addressing social norms, and our thoughts on the meaning of what we found for applied EE practice.

\section{Entertainment-Education Case Studies}

\section{India}

Kyunki...Jeena Issi Ka Naam Hai (Because... That's What Life Is; abbreviated Kyunki...) was an Indian television drama serial that ran for 501 episodes from 2008 to 2011 on Doordarshan, the public service broadcast network. UNICEF India developed the program with information from Facts for Life, the global maternal and child health initiative spearheaded by international partners including UNDP, UNESCO, UNAIDS, WFP, WHO, and the World Bank. Key educational messages included safe motherhood, breastfeeding, immunization, HIV/AIDS, child protection, girls' education, child marriage, and others designed to improve the lives of women and children. Doordarshan (the national broadcaster) aired three new half hour episodes of Kyunki... each week. 
Kyunki ... struck a unique balance between social messaging and primetime entertainment, through a compelling storyline involving five key protagonists. Three of the five lead characters were females and included Savita, Shabnam, and Kamla as community health workers in the fictional village of Rajpura. Savita is portrayed as an urban dweller who struggles to find her way in a traditional rural setting. Shabnam, herself a victim of domestic violence, is a strong champion of women and child rights, and Kamla is a young widow who rises above societal restrictions to serve as the local health volunteer. The drama also included Phoolwati, the local village head, who is appointed as a figurehead but over the course of the drama finds her voice and stands up for the people of Rajpura. The fifth role model is Hiralal, a humorous and down to earth schoolteacher who emerges as the champion for education in his village. These protagonists are challenged at every term by Bade Sahab, the all-powerful village patriarch, and the main negative character. The serial also included Meena, a fun loving and precocious girl and her group of friends. Kyunki... included Bollywood-style entertainment including high drama, comedy, romance, as well as music, while showcasing positive social change at the individual and community levels. The serial emerged as the most watched show across all channels in India in its time band (according to Television Audience Measurement-TAM), with a reach of over 145 million people and 61 percent of viewers being women in the age group of 15-35.

Suruchi led the evaluation efforts for Kyunki... (Sood et al., 2015). The research design included three cross-sectional quantitative studies: a baseline, completed before the program aired; a midline, conducted after approximately 260 episodes; and an endline, after the conclusion of the television serial, as well as concurrent mixed-methods monitoring. Data were collected from approximately 9000 people at each time point: women, their husbands, and their mothers-in-law who resided in UNICEF priority states, for a total sample size of over 27,000. Amy and Suruchi worked together with colleagues on a subsequent study using the evaluation data that looked at exposure to Kyunki... and social norms when Amy was a doctoral student under Suruchi's tutelage (Riley et al., 2017a). The Kyunki... evaluation measured one social norms construct: descriptive norms, albeit many times over across key messages.

What worked well in this evaluation is that the social norms questions were relatively straightforward and the analysis was uncomplicated and easy to understand. But we experienced a major challenge. This program's evaluation was designed before newer scholarship regarding social norms 
measurement emerged and, as a result, only descriptive norms were measured using a single measure. As the more recent literature indicates, social norms are much more nuanced and descriptive norms alone are likely insufficient for making claims regarding change over time.

\section{Mozambique}

Ouro Negro (Black Gold) is a radio program in Mozambique that began broadcasting across the country in 2015 and is still on the air as of this publishing. UNICEF Mozambique developed the program in partnership with WFP, UNFPA, the Ministry of Education, PCI Media Impact, and Radio Mozambique. Like the Kyunki... project in India, the Facts for Life global campaign informed Ouro Negro's content on maternal and child health. New episodes are broadcast nationally twice a week in Portuguese and district-level content includes radio call-in shows in local languages and digital media components.

Ouro Negro takes place in the fictional town of Jambolane, which is confronted by the arrival of a foreign mining company. The plot follows the meeting of two families, one modern and one traditional, and the conflicts that ensue between rural and modern life. The key protagonists include: Jambo, the village chief; Quim, Jambo's son and a successful football player; Almeida, the coal mining plant manager; Isabel, a female medical doctor; Lura, a young girl with a passion for dancing; and Anita, a 13-year-old student. The creative team designed the characters to be similar to members of the audience and to model pro-social and educational themes throughout their story arcs and a theory of change encompassing levels of the social ecological model. The radio drama airs across 118 stations across the country, including call-in shows in local languages, and digital components on social media.

UNICEF Mozambique contracted Suruchi (as principal investigator) and Amy (as project manager) to evaluate the impact of the first year of Ouro Negro. Together, Suruchi and Amy designed a mixed-methods monitoring and evaluation framework to determine if the program was effective and what social and behavior change could be attributed to Ouro Negro. The evaluation included two arms: a survey arm, which employed a population-based, longitudinal, single pre-test, single post-test panel design, and a focus group arm, which utilized a cross-sectional research design. The study included data from 1910 women aged 15-34 who responded to the survey and 512 men and women aged $15+$ who 
participated in focus groups. Amy subsequently analyzed the data to look at the role of social norms as part of her doctoral dissertation; Suruchi chaired Amy's dissertation committee (Riley, Sood, \& Sani, 2019).

The Ouro Negro evaluation measured five social norms constructs: descriptive norms, injunctive norms, benefits, sanctions, and reference groups. We used various ways of measuring each of the constructs in the surveys including testing closed-ended questions designed to measure benefits and sanctions, for example: "Please tell me some of the benefits of using latrines for defecation." We measured the same constructs in focus groups that contained three participatory activities. The first activity (called "Complete the Story") was a narrative tool whereby focus group participants were provided with two scenarios mirrored by those experienced by the Ouro Negro radio program protagonists and asked to think about and report on what they would do if they themselves were faced with these scenarios. The second activity was a social network mapping activity where participants mapped who they talked to and trusted regarding the program topics. Suruchi designed the final activity, " $2 \times 2$ Tables," which she has also used in other countries, to have participants work through a series of questions to unfold the existence, persistence, and changes in social norms on the topics over time. $2 \times 2$ Tables are a written, participatory research method.

Several things worked well in this case study. Social norms theorizing had matured in the time since the Kyunki... project and we aimed to include many more constructs in our evaluation that better matched the recent literature. Our mixed-methods efforts worked well to measure not only if social norms were changing, but how and why such changes occurred through a combination of data sources. A logistical detail from this case study that worked well was how we handled the fieldwork for this project. We traveled together for our first trip to Mozambique. Again, Amy was a doctoral student at the time and it was important for her to learn from Suruchi from this applied research project and for all team members to be present for the inception of the project. When it came time for a subsequent international trip, Amy traveled alone to work with the local team. By this time, the local team knew and trusted Amy and she was able to handle her tasks with Suruchi's assistance when needed from afar. We have both found that trust is vital to the success of our research and the programs that we are fortunate enough to evaluate.

Our biggest challenge from this case study, however, was exposure. Although we had a robust study design that included following the same 
people over time, only 206 of 1910 participants at endline listened to Ouro Negro. What does this mean? Practically, this means that you can have strong research studies designed to measure all of the latest fancy ideas on social norms, but if audiences either don't listen to or don't like your show, it doesn't matter. A strong research study cannot make up for a program that audiences do not find engaging. (Note: That is not to say Ouro Negro was or is a failure. To the contrary, the program continues as of this writing. What we found after one year of broadcast, however, were low levels of exposure and engagement.) It is therefore critical to put the "entertainment" in entertainment-education first. To change social norms, we must first tell good stories. The storytelling really matters!

\section{Bangladesh}

From 2017 to 2019, Suruchi provided technical assistance to the James P. Grant School of Public Health in Dhaka, Bangladesh, for the evaluation of a 26-episode social and behavior change communication transmedia initiative, including an EE television show Icchedana (On the Wings of Wishes). This project was a result of collaboration between the Government of Bangladesh (GoB), UNICEF, Asiatic, MCL, PCI Media, and BRAC JHSPH. The EE TV show portrayed the lives of a group of young Bangladeshi girls who face and overcome challenges and risks of adolescence such as child marriage, sexual harassment, menstrual hygiene management, nutrition, and adverse gender norms through sports. Icchedana focused on empowering adolescents and facilitating an enabling environment for their families and communities to support positive behaviors and norms. In addition, the program delivered on-the-ground community engagement interventions implemented in high child marriage areas mobilized around key behaviors and messages. Icchedana aired on five national channels, including the national broadcasting network as well as satellite channels, and reached over six million people. The episodes were also hosted on UNICEF and the Ministry of Women and Children's Affairs' (MoWCA) social media platforms and on YouTube. The UNICEF Bangladesh Facebook platform engaged over 2 million people. Community efforts reached more than 320,000 parents and communities to create an enabling environment to support adolescent empowerment. Private sector partners contributed more than 1.5 million USD through sponsoring media dissemination of Icchedana. Additionally, Icchedana won numerous awards including a Bronze Telly Award where it was recognized as a 
standard bearer of video excellence and several accolades at the Bangladesh Brand Forum Commward 2019.

The Icchedana evaluation included a pre and post design. A total of 1164 households with four respondents per household $(n=4356)$ were involved in the baseline study. The recently concluded endline study (2019) utilized a longitudinal panel design and involved 3905 respondents. The evaluation measured descriptive norms, injunctive norms, rewards, and sanctions over a range of normative issues, including child marriage, prioritizing boys' education over girls in case of financial restraints, restricting girls' mobility to protect from sexual harassment, girls/women earnings contributing financially toward the family, and equal participation of men and women in the decision-making process.

One of the key challenges that emerged from the Icchedana evaluation was that the baseline data did not ask questions on social norms in the same in-depth manner as the endline. The lack of pre and post intervention data for some indicators, therefore, made it difficult to track change over time in social norms that could be attributed to exposure to the Icchedana evaluation and/or that Icchedana contributed to. Another unique challenge related to asking about norms surrounding specific development issues, such as child marriage, education for girls, and sexual harassment independent of gender norms. Gender norms cross-cut education, protection, and health; they are also a primary driver for child marriage. Hence, social norms programming for adolescent development has to include a gender focus that involves transforming the ways gender is constructed for girls and boys.

\section{Zambia}

Our last case study is from research that Amy led in Zambia. In 2018, the Grantham Foundation awarded a grant to Population Media Center (PMC) to enhance PMC's capacity to affect social norm change and measurably demonstrate the impact of their global EE programs. PMC partnered with Amy as the academic lead on the project. After reviewing the scholarly literature and designing a social norms strategy for PMC, Amy designed a pilot study to answer the following research question: Are vignettes a valid methodological approach for measuring social norms to inform EE research and practice? A vignette is a short narrative that describes a hypothetical person within a specific social context (Finch, 1987; Alexander \& Becker, 1978; Jenkins, Bloor, Fischer, Berney, \& 
Neale, 2010). Applied in research, participants respond to questions following a vignette stimulus through close-ended survey responses or openended qualitative responses in interviews or focus groups (Wilson \& While, 1998; Barter \& Renold, 1999). Amy and her colleagues chose to test vignettes based on their likeness to the narratives inherent to EE. They chose family planning, as the topic has been and continues to be one of the most common topics covered in EE by both PMC and other organizations around the world (Sood, Riley, \& Alarcon, 2017). They chose Zambia as PMC had an ongoing EE program in two languages in the country at the time of the research.

Amy and her colleagues designed a mixed-methods cross-sectional study to test the validity of vignettes as a social norms measurement tool in one purposively selected rural and one purposively selected urban district in the Central Province of Zambia, where PMC was concurrently airing the EE radio program. Kwishilya ("Over the Horizon") was a 156-episode serial drama funded by USAID that aired from 2019 to 2020 and addressed the topics of family planning, adolescent reproductive health, education, child marriage, HIV/AIDS, and gender-based violence. Together with a local research partner, we collected survey data from 438 women aged 19-34 who had listened to at least one episode of PMC's program but had never answered questions about the radio program before (i.e., were not part of separate monitoring and evaluation activities) and focus group data from 135 women who met the same inclusion criteria and were part of 16 focus group discussions spread across the two districts.

This study measured all six social norms constructs outlined in this chapter. As this was a validation study, we threw in the kitchen sink with this study. We scoured the literature and used several methods for each of the constructs to compare results and determine which measurement approach might work best in the future. While the results are in progress as of this writing, overall, we found vignettes may be an appropriate tool for measuring social norms on topics in EE narratives with existing characters and stories. But we experienced two challenges: one related to testing and one practical challenge. In terms of testing, while it was a fruitful academic exercise to test many different question formats on the same topic, we found participants experienced fatigue at answering essentially the same question in several different ways. While we cannot say how many questions are "ideal" to measure social norms in research and 
evaluation of EE projects, we do not think quite so many questions are necessary in all cases.

The other challenge experienced was a practical one. In the middle of this project, Amy learned she was pregnant with her first child (she and her husband were clearly not utilizing the modern contraceptive methods promoted by Kwishilya). Like the other case studies outlined here, our research typically requires in-country fieldwork where we work together with our local partners to plan data collection and train enumerators and supervisors. The fieldwork for this project was planned at the end of Amy's pregnancy and she was unable to travel to Zambia. Thankfully, Suruchi's talented research manager Sarah Stevens was available to consult on this project. Sarah traveled on Amy's behalf and Amy spent many early mornings on WhatsApp and email communicating with the team from afar. EE research can be unpredictable for a multitude of reasons and having a keen sense of flexibility is absolutely fundamental for this type of work.

\section{Lessons Learned and Best Practices}

Our collective experiences working on these four EE case studies include a plethora of lessons learned for social norms theory, research, and practice. The following are our "top five" for academics and EE practitioners alike.

\section{Conduct Rigorous Research, Starting with Formative Research}

Folks working to develop and produce effective EE understandably want to demonstrate that their programs have an impact. When it comes to social norms, EE programs should first determine if the "educational" or didactic topic at hand is actually influenced by social norms, through rigorous formative research. Although it is de rigueur as of this publishing to talk and write about social norms, this is a moot point if the topic at hand isn't really influenced by social norms in the first place. Not all EE programs are going to change social norms, and that is OK! Social norms can be said to influence a behavior only when expectations and behaviors share a causal relationship. One has to practice a behavior because they believe a majority of individuals in their social networks are engaging in the behavior and also that these individuals expect one to perform the behavior. If the topic is thus influenced by social norms, we think researchers should tackle all of the applicable social norms constructs outlined in this chapter, 
but without burden on the research participant. Social norms are complex and exist at the intersection of perceptions of what others do, what others expect a person to do, and what the tangible and intangible rewards of compliance or defiance of a given social norm are. For example, social norms may prevail because individuals feel that others in their community behave in a certain manner, even when it is contradictory to their own values. One way to counteract this is to message accurately, to convince audiences that "others" hold the same values and principles as them. EE has proven successful over and over again, in addressing not just individual behaviors but by fundamentally changing determinants such as social and gender norms that underlie harmful practices. There are nuances and contradictions between personal approval which is generally more positive than approval of "others" in the community or "others" whose opinions matter. A successful EE program has to balance the nuances and contradictions between personal beliefs and attitudes and social and gender norms.

\section{Work in Partnership with Strong Local Researchers}

The research studies outlined in these case studies were conducted using a stakeholder framework that includes international aid organizations (such as UNICEF and The Grantham Foundation), international universities (i.e., our academic institutions), local creative talent, and local research teams. Each of these stakeholders contributes to the success of EE programs by providing their specific areas of expertise. The expertise that we bring as international researchers is in the theory and evaluation of EE. Critical to the success of our work is a strong local research partner. Our local partners are key to conducting this research and, in terms of social norms, to piloting tools and confirming cultural interpretations of questions. The constructs outlined in this chapter are complex ideas that frustratingly have overlapping terms to describe similar ideas, but it is critical to include members of the community to confirm research questions are asking what we think they are asking. Translation and back translation are important, particularly in polyglot settings where nuance can be easily lost. And cognitive interviewing is helpful to make sure research items are processed and understood by members of the audience. Essentially, our viewpoint is that social norms work (and international research in general) is only possible through reciprocal and respectful partnerships with strong 
local researchers. As EE work is scaled up over time, it is our hope that we eventually work ourselves out of our jobs and build capacity among local teams to conduct research independent of us.

\section{Include the Voices of Your Intended Audience Through Participatory Research}

Our social norms research has found that it is crucial to have the voices of the intended audience at the table. Participatory research methods are bottom up approaches and one way to include the voices of audiences. In participatory research, members of affected communities, particularly members of traditionally marginalized and vulnerable groups, can identify indicators of change and hypothesize solutions themselves. We have written about participatory research methods elsewhere (Riley, Sood, \& Robichaud, 2017b; Sood, Cronin, \& Kostizak, 2018) and are of the opinion that participatory research methods can be used at any stage of evaluation (i.e., formative, process, and/or impact evaluation) to amplify the voices of impacted individuals and communities.

\section{Use Storytelling for Storytelling}

EE has a unique "secret sauce" in the world of social and behavior change communication: storytelling. At the heart of every EE program is a cast of positive, negative, and transitional characters designed to be like members of the primary audience and carefully planned, entertaining storylines. EE programs are typically developed with top local creative talent, including producers, writers, and actors. We think that this built in capacity for good storytelling can be tapped for research efforts for measuring social norms, as well as other indicators. In other words, use storytelling for storytelling. Vignettes (described earlier) are one example of a storytelling methodology where research participants read or listen to a short story stimulus and respond to questions to elicit their attitudes, beliefs, and social norms. While our research has shown that vignettes "work" as a way to garner such responses, we think such efforts could be strengthened even further with the inclusion of EE creative talent in this process-for example, by having scriptwriters design vignette research questions and actors record focus group prompts. It seems to us like a natural fit to utilize creative EE teams not only in the design and implementation of EE programs, but also in evaluation and research efforts. 


\section{Merge Theory and Practice}

Theory and practice must coexist. EE research and theorizing must not exist in an erudite vacuum, and instead must be accessible to practitioners. What this means practically is that we need a shared lexicon (i.e., less overlapping and confusing terms) and a space for open dialogue between researchers and practitioners. Together we can interpret and communicate our findings so they may be translated into real-world outcomes. EE is an exciting and creative strategy that can change individuals, impact communities, and shift social norms. It takes time, for sure. Change does not happen overnight, especially when one is attempting to raise awareness around practices that are intertwined with religion, culture, tradition, and self-identity. To expect radical shifts in norms through one EE program would be naïve. But in order to keep propelling the field forward, we must align our efforts in a state of continuous improvement where practice informs research and research informs practice.

\section{REFERENCES}

Ajzen, I., \& Fishbein, M. (1980). Understanding attitudes and predicting social behavior. Prentice Hall.

Alexander, C. S., \& Becker, H. J. (1978). The use of vignettes in survey research. Public Opinion Quarterly, 42(1), 93-104.

Bandura, A. (1977). Social learning theory. Prentice Hall.

Barter, C., \& Renold, E. (1999). The use of vignettes in qualitative research. Social Research Update, 25, 1-4. Retrieved from http://sru.soc.surrey.ac.uk/ SRU25.html

Bendor, J., \& Swistak, P. (2001). The evolution of norms. American Journal of Sociology, 106(6), 1493-1545.

Bicchieri, C. (2006). The grammar of society: The nature and dynamics of social norms. Cambridge University Press.

Bicchieri, C. (2016). Norms in the wild: How to diagnose, measure, and change social norms. Oxford University Press.

Busselle, R., \& Bilandzic, H. (2009). Measuring narrative engagement. Media Psychology, 12(4), 321-347.

CARE. (2017). Applying theory to practice: CARE's journey piloting social norms measures for gender programming. Cooperative for Assistance and Relief Everywhere, Inc. (CARE). Retrieved from http://gender.care2share.wikispaces.net/file/view/care-social-norms-paper-web.pdf 
Cialdini, R. B., Reno, R. R., \& Kallgren, C. A. (1990). A focus theory of normative conduct: Recycling the concept of norms to reduce littering in public places. Journal of Personality and Social Psychology, 58(6), 1015-1026.

Cohen, J. (2001). Defining identification: A theoretical look at the identification of audiences with media characters. Mass Communication \& Society, $4(3), 245-264$.

Costenbader, E., Lenzi, R., Hershow, R. B., Ashburn, K., \& McCarraher, D. R. (2017). Measurement of social norms affecting modern contraceptive use: A literature review. Studies in Family Planning, 48(4), 377-389.

Finch, J. (1987). The vignette technique in survey research. Sociology, $21(1), 105-114$.

Frank, L. B., Murphy, S. T., Chatterjee, J. S., Moran, M. B., \& BaezcondeGarbanati, L. (2015). Telling stories, saving lives: Creating narrative health messages. Journal of Health Communication, 30, 154-163.

Goldstein, N. J., Cialdini, R. B., \& Griskevicius, V. (2008). A room with a viewpoint: Using social norms to motivate environmental conservation in hotels. Journal of Consumer Research, 35(3), 472-482.

Green, M. C., \& Brock, T. C. (2000). The role of transportation in the persuasiveness of public narratives. Journal of Personality and Social Psychology, $79(5), 701-721$.

Heise, L., \& Cislaghi, B. (2017). Transforming gender norms to achieve gender equity: What is the role of social norms theory? Discussion paper. The LancetStanford Working Group, Stanford. Retrieved from https://researchonline. lshtm.ac.uk/id/eprint/4646481/

Horton, D., \& Wohl, R. R. (1956). Mass communication and para-social interaction: Observations on intimacy at a distance. Psychiatry, 19(3), 215-229.

Institute for Reproductive Health. (2019). Resources for measuring social norms: $A$ practice guide for program implementers. Learning Collaborative to Advance Normative Change. Washington, DC.

Jenkins, N., Bloor, M., Fischer, J., Berney, L., \& Neale, J. (2010). Putting it in context: The use of vignettes in qualitative interviewing. Qualitative Research, 10(2), 175-198.

Kaggwa, E. B., Diop, N., \& Storey, J. D. (2008). The role of individual and community factors among women in union in Mali. International Family Planning Perspectives, 34(2), 79-88.

Kincaid, D. L. (2004). From innovation to social norm: Bounded normative influence. Journal of Health Communication: International Perspectives, 9(S1), 37-57.

Lapinski, M. K., \& Rimal, R. N. (2005). An explication of social norms. Communication Theory, 15(2), 127-147.

Mackie, G., Moneti, F., Shakya, H., \& Denny, E. (2015). What are social norms? How are they measured? Working paper. UNICEF/University of California San Diego Center on Global Justice. 
Montano, D., \& Kasprzyk, D. (2008). Theory of reasoned action, theory of planned behaviour and the integrated behavioural model. In K. Glanz, B. Rimer, \& K. Viswanath (Eds.). Health behaviour and bealth education. Theory research and practice, Jossey-Bass.

Petit, V., \& Zalk, T. (2019). Everybody wants to belong. A practical guide to tackling and leveraging social norms in behavior change programming. Retrieved from https://www.unicef.org/mena/media/4716/file/MENA-C4DReportMay2019.pdf.pdf

Poindexter, D. O. (2004). A history of entertainment-education, 1958-2000. In A. Singhal, M. J. Cody, E. M. Rogers, \& M. Sabido (Eds.), Entertainmenteducation and social change (pp. 21-37). Lawrence Erlbaum Associates, Inc.

Riley, A. H., Sood, S., Mazumdar, P. D., Choudary, N., Malhotra, A., \& Sahba, N. (2017a). Encoded exposure and social norms in entertainment-education. Journal of Health Communication, 22(1), 66-74.

Riley, A. H., Sood, S., \& Robichaud, M. (2017b). Participatory methods for entertainment-education: Analysis of best practices. Journal of Creative Communications, 12(1), 62-76.

Riley, A. H., Sood, S., \& Sani, M. (2019). Narrative persuasion and social norms in entertainment-education: Results from a radio drama in Mozambique. Health Communication, 35(8), 1023-1032.

Rimal, R. (2008). Modeling the relationship between descriptive norms and behaviors: A test and extension of the Theory of Normative Social Behavior (TNSB). Health Communication, 23(2), 103-116.

Rimal, R., \& Lapinkski, M. (2015). A re-explication of social norms, ten years later. Communication Theory, 25(4), 393-409.

Rimal, R., Lapinski, M., Cook, R., \& Real, K. (2005). Moving toward a theory of normative influences: How perceived benefits and similarity moderate the impact of descriptive norms. Journal of Health Communication, 10(5), 433-450.

Rimal, R., \& Real, K. (2005). How behaviors are affected by perceived norms. A test of the theory of normative social behavior. Communication Research, $32(3), 389-414$.

Rogers, E. M. (2003). Diffusion of innovations (5th ed.). Simon \& Schuster.

Rosenstock, I. M. (1974). The health belief model: Origins and correlates. Health Education Monographs, 2(4), 328-335.

Ryerson, W. N. (1994). Population communications international: Its role in family planning soap operas. Population and Environment, 15(4), 255-264.

Sedlander, E., \& Rimal, R. N. (2019). Beyond individual-level theorizing in social norms research: How collective norms and media access affect adolescents' use of contraception. Journal of Adolescent Health, 64(4), S31-S36.

Singhal, A., Obregon, R., \& Rogers, E. M. (1995). Reconstructing the story of Simplemente Maria, the most popular telenovela in Latin America of all time. International Communication Gazette, 54, 1-15. 
Singhal, A., \& Rogers, E. M. (1988). Television soap operas for development in India. International Communication Gazette, 41, 109-126.

Singhal, A., \& Rogers, E. M. (1999). Entertainment-education: A communication strategy for social change. Lawrence Erlbaum Associates.

Singhal, A., \& Rogers, E. M. (2002). A theoretical agenda for entertainmenteducation. Communication Theory, 12(2), 117-135.

Singhal, A., \& Rogers, E. M. (2004). The status of entertainment-education worldwide. In A. Singhal, M. J. Cody, E. M. Rogers, \& M. Sabido (Eds.), Entertainment-education and social change (pp. 3-20). Lawrence Erlbaum Associates Inc.

Sood, S. (2002). Audience involvement and entertainment-education. Communication Theory, 12(2), 153-172.

Sood, S., Cronin, C., \& Kostizak, K. (2018, November). Participatory research toolkit. Rain Barrel Communications. Retrieved from https://www.rainbarrelcommunications.com/wp-content/uploads/2018/11/ParticipatoryResearch-Toolkit-Rain-Barrel-Communications.pdf

Sood, S., Riley, A. H., \& Alarcon, K. (2017). Entertainment-education and health and risk messaging. In R. Parrott (Ed.), Oxford research encyclopedia of communication. Oxford University Press.

Sood, S., Riley, A. H., Mazumdar, P. D., Choudary, N., Malhotra, A., \& Sahba, N. (2015). From awareness-generation to changing norms: Implications for entertainment-education. Cases in Public Health Communication o Marketing, 8, 3-26.

Sood, S., et al. (2020). ACT: An evidence-based macro framework to examine how communication approaches can change social norms around female genital mutilation. Frontiers in Communication, 5, 29. https://doi.org/10.3389/ fcomm.2020.00029

Storey, J. D., \& Kaggwa, E. B. (2009). The influence of changes in fertility related norms on contraceptive use in Egypt 1995-2005. Population Review, $48(1), 1-19$.

Wang, H., \& Singhal, A. (2018). Audience-centered discourses in communication and social change: The 'voicebook' of Main Kuch Bhi Kar Sakti Hoon, an entertainment-education initiative in India. Journal of Multicultural Discourses, 13, 176-191. https://doi.org/10.1080/17447143.2018.1481857

Wilson, J., \& While, A. E. (1998). Methodological issues surrounding the use of vignettes in qualitative research. Journal of Interprofessional Care, 12(1), 79-86.

World Health Organization. (2010). Violence prevention: The evidence. Retrieved from http://www.who.int/violence_injury_prevention/violence/4th_milestones_meeting/evidence_briefings_all.pdf 
Open Access This chapter is licensed under the terms of the Creative Commons Attribution-NonCommercial-NoDerivatives 4.0 International License (http:// creativecommons.org/licenses/by-nc-nd/4.0/), which permits any noncommercial use, sharing, distribution and reproduction in any medium or format, as long as you give appropriate credit to the original author(s) and the source, provide a link to the Creative Commons licence and indicate if you modified the licensed material. You do not have permission under this licence to share adapted material derived from this chapter or parts of it.

The images or other third party material in this chapter are included in the chapter's Creative Commons licence, unless indicated otherwise in a credit line to the material. If material is not included in the chapter's Creative Commons licence and your intended use is not permitted by statutory regulation or exceeds the permitted use, you will need to obtain permission directly from the copyright holder. 